\title{
Gestión de residuos en hemodiálisis
}

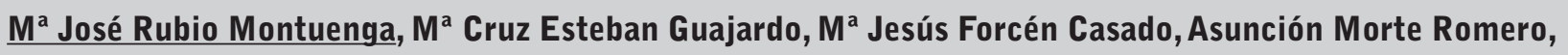 \\ Marta Julvez Cabrerizo
}

Hospital "Ernest LLuch". Calatayud. Zaragoza

\section{Introducción:}

Con motivo de la utilización en nuestra Unidad de nuevos productos para el tratamiento de hemodiálisis nos planteamos si realizábamos una correcta eliminación de los residuos generados. Según la Constitución Española los ciudadanos tenemos derecho a la protección de la salud y a disfrutar de un medio ambiente adecuado para el desarrollo personal, siendo competencia de los poderes públicos garantizar dichos derechos. En cada comunidad autónoma existen leyes que regulan las exigencias básicas que deben de respetarse en cada una de las etapas de la gestión de los residuos sanitarios que garanticen la protección de la salud pública y el medio ambiente, desde su generación a su eliminación final. Decidimos conocer la normativa de la eliminación de residuos sanitarios de nuestro hospital, evaluar si lo hacíamos correctamente y modificar actuaciones si fuese necesario.

\section{Objetivos:}

- Realizar una adecuada gestión de todos los residuos generados.

- Contribuir a la mejora del medio ambiente respetando la normativa vigente.

- Unificar criterios a la hora de eliminar los residuos, disminuyendo la variabilidad.

- Disminuir los costes hospitalarios.

\section{Material y método:}

Nuestra Unidad cuenta con 12 puestos de hemodiálisis. El personal lo constituyen 4 enfermeras, 2 ne- frólogos, 1 supervisora, 1 auxiliar de enfermería y 1 limpiadora. El personal de enfermería comenzamos realizando reuniones periódicas, en un total de 20, en las cuales hicimos una relación de qué residuos se generaban durante la sesión de hemodiálisis y cómo los eliminábamos. En estas reuniones detectamos los puntos que hacíamos correctamente y los que debíamos modificar y/o unificar. Ante la diversidad de criterios nos pusimos en contacto con el servicio de Prevención de Riesgos Laborales, con el responsable de eliminación de residuos de nuestro hospital y con fabricantes para realizarlo de forma adecuada. Para ello seguimos la Clasificación de residuos que rige en nuestra Comunidad:

- Grupo I: Residuos asimilables a urbanos.

- Grupo II: Residuos sanitarios no específicos.

- Grupo III: Residuos sanitarios específicos o de riesgo.

- Grupo IV: Cadáveres y restos humanos.

- Grupo V: Residuos químicos.

- Grupo VI: Residuos citostáticos. Grupo VII: Residuos radioactivos.

\section{Resultados:}

Mejoramos el reciclado de papel y plásticos. Eliminación de las ampollas de cristal al contenedor de riesgo. Modificamos la eliminación de mascarillas de ventiloterapia, bolsas de biofiltración, bolsas de suero, las cuales se eliminaban como de riesgo y pueden ir en asimilables a urbanos. Se adecuó el número de contenedores y su ubicación. Reducción del peso en residuos de riesgo con la consecuente disminución del gasto hospitalario. Las reuniones periódicas han servido para unificar criterios. 


\section{Conclusión:}

Una adecuada gestión de residuos repercute en el medio ambiente y en el coste hospitalario. ¡Quien genera el residuo es responsable de su clasificación!.

\section{Referencias Bibliográficas}

1. Plan Integral de Gestión de residuos de la Comunidad Autónoma de Aragón. Eulalia Teresa Lope Andrea, $\mathrm{M}^{\mathrm{a}}$ Isabel Duran Muñoz, Esperanza Barriouso, pedro Diaz, Elisabeth Coll Torreo. Papel de la Enfermería en la minimización de residuos sanitarios en una Unidad de Nefrología. Comunicaciones presentadas al XXX Congreso nacional de la Sociedad Española de Enfermería Nefrológica. Málaga 2005. 